\title{
Characterization of Lycium barbarum L. berry cultivated in North Macedonia: A chemometric approach
}

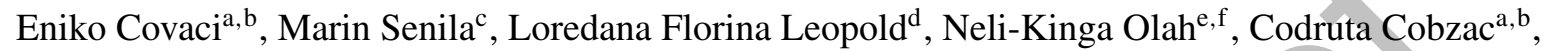 \\ Violeta Ivanova-Petropulos ${ }^{\mathrm{g}}$, Biljana Balabanova ${ }^{\mathrm{g}}$, Oana Cadar ${ }^{\mathrm{c}}$, Anca Becze ${ }^{\mathrm{c}}$, Michaela Ponta ${ }^{\mathrm{a}, \mathrm{b}}$, \\ Augustin Catalin Mot $^{\mathrm{a}, \mathrm{b}}$ and Tiberiu Frentiu ${ }^{\mathrm{a}, \mathrm{b}, *}$ \\ ${ }^{a}$ Babes-Boyai University, Faculty of Chemistry and Chemical Engineering, Cluj-Napoca, Romania \\ ${ }^{\mathrm{b}}$ Research Center for Advanced Chemical Analysis, Instrumentation and Chemometrics, Cluj-Napoca, Romania \\ ${ }^{\mathrm{c}}$ INCDO-INOE 2000 National Institute for Research and Development of Optoelectronics Bucharest, Research \\ Institute for Analytical Instrumentation, Cluj-Napoca, Romania \\ ${ }^{\mathrm{d}}$ University of Agricultural Sciences and Veterinary Medicine, Faculty of Food Science and Technology, \\ Cluj-Napoca, Romania \\ ${ }^{\mathrm{e}}$ Vasile Goldis Western University of Arad, Faculty of Pharmacy, Arad, Romania \\ ${ }^{\mathrm{f}} \mathrm{SC}$ PlantExtrakt SRL, Cluj, Romania \\ ${ }^{\mathrm{g}}$ Goce Delčev University, Faculty of Agriculture, Štip, Republic of North Macedonia
}

\begin{abstract}
.
BACKGROUND: Lycium barbarum L. has received considerable attention due to nutritional value of berries and its cultivation in Europe has attracted growing interest.

OBJECTIVE: The aim of the study was characterization of Lycium barbarum L. berry cultivated in North Macedonia in terms of nutritional and functional properties and comparison with Lycium chinense M. variety.

METHODS: Minerals, total proteins, sugars, antioxidant activity, fatty acids, carotenoids and polyphenols were determined and lipid indices were evaluated. Principal Component Analysis was used to describe variability of composition, while heat map to recognize the parameters significantly different for varieties.

RESULTS: Lycium barbarum L. cultivated in North Macedonia represents a rich source of $\mathrm{K}, \mathrm{Cu}, \mathrm{Mn}, \mathrm{P}, \mathrm{Zn}, \mathrm{Mg}, \mathrm{Fe}$ and antioxidant compounds. Polyunsaturated fatty acids (mainly linolenic acid) were dominant in oil resulting in very low atherogenic and thrombogenic indices. A variability of $35.1 \%$ was ascribed to minerals, carbohydrates and proteins, $22.3 \%$ to $\omega-6$ fatty acids and lipid indices of oil, $19.4 \%$ to nutrients with antioxidant activity and $13.4 \%$ to $\omega-3$ fatty acids (n-3 and n-3/n-6 ratio).

CONCLUSIONS: Chemometric analysis highlighted significant differences in terms of inorganic nutrients, antioxidant capacity, proteins, sugar profile and lipid indices in Lycium barbarum L. compared to Lycium chinense M.
\end{abstract}

Keywords: Lycium barbarum L., Lycium chinense M., mineral nutrient, fatty acid, antioxidant activity, unsupervised chemometrics

${ }^{*}$ Corresponding author: T. Frentiu, E-mail: ftibi@ chem.ubbcluj.ro. 


\section{Introduction}

The nutritional and beneficial health effects of fruits were often emphasized [1-6]. Lycium barbarum L. belonging to the Solanaceae family has $1-2 \mathrm{~cm}$ long reddish-orange ellipsoid berries of sweet-and-tangy flavor with native area probably in Southeastern Europe, while Lycium chinense M. has its origin in Southwest Asia (China). Due to its special nutritional composition (free sugars, carotenoids, polyphenols, flavonoides, vitamins, fatty acids, minerals, proteins, etc.) with health benefits such as immunity enhancement, antioxidant, anti-aging and anti-tumor effects, Goji berry has been proposed as functional food and included in the category of "superfoods" [4, 7-17]. Other major aspects of the medicinal quality of Goji fruit are heart disease risk reduction, hypoglycaemic, hypolipidemic and neuroprotective effects, prevention of some eye diseases and male fertility facilitation [18-20]. However, Goji berry consumption could be associated to risk of allergic reactions [21].

Goji have been an important part of the traditional Chinese medicine for more than 2000 years. Rapid increase in consumption in Europe is noticed at the beginning of the twenty-first century [11,22]. Goji berries are consumed fresh, dried, processed into juice [4, 9, 10, 13, 23], as ingredient in snack, yoghurt and cereal bar [24] or as capsules and concentrated extracts [4]. Goji organic extract is added as natural antioxidant in extra-virgin olive oil and soybean oil to improve the oxidative stability and sensory profile such as taste, color or turbidity [24-27].

In Asia Goji is cultivated mostly in China, Taiwan and Japan, while in Europe most frequently in Southeastern countries. There is growing interest in Goji cultivation in Greece [10, 15], Italy [8, 13, 16], Romania [12] and Bulgaria [28]. In recent years, Goji cultivation expanded to other European countries, such as Switzerland [11], Spain [4] and Poland [9]. Chemical composition of Goji fruits differs by variety and cultivation region so that the potency of their bioactivities may also be different.

The aim of this study was the evaluation for the first time of Lycium barbarum L. berry cultivated in North Macedonia and comparison with Lycium chinense M. variety. Functional properties were assessed through fatty acids (FAs) profile, lipid indices, antioxidant activity of methanolic extracts, total phenol content (TPC), total carbohydrate content (TCC), phenolic, sugar and carotenoid profiles. Several nutritive elements and total proteins were evaluated and their intake was related to Recommended Daily Allowance (RDA). Principal Component Analysis (PCA) and heat map were used to describe variability of chemical composition of Lycium barbarum L. and recognize the parameters significantly different from Lycium chinense M.

\section{Materials and methods}

\subsection{Chemicals}

All reagents, ICP multi-elemental standard solution IV Certipur $1000 \mathrm{mg} / \mathrm{L}$ ( 23 elements), single element standard solutions $1000 \mathrm{mg} / \mathrm{L}$ of $\mathrm{As}, \mathrm{Hg}, \mathrm{Mo}, \mathrm{P}$ and $\mathrm{S}$, and multi-component standard of fatty acid methyl esters (FAMEs) Mix C8-C24 were purchased from Merck (Darmstadt, Germany). The ACL-Kit for photochemical luminescence (PCL method) used to estimate antioxidant activity was purchased from Analytik Jena (Germany). Matrix modifiers $10 \% \mathrm{NH}_{4} \mathrm{H}_{2} \mathrm{PO}_{4}, 1 \% \mathrm{Mg}\left(\mathrm{NO}_{3}\right)_{2}$ and $1 \% \mathrm{Pd}\left(\mathrm{NO}_{3}\right)_{2}$ used in atomic absorption spectrometry were purchased from Perkin Elmer (Shelton, USA). Ultrapure water (18 $\mathrm{M} \Omega \mathrm{cm}$ resistivity) (Millipore, Bedford, USA) was used throughout the experiments.

\subsection{Goji berry samples}

Berries of Lycium barbarum L. variety (8 samples) were collected during July-September 2017 from 5 organic plantations located around the town of Kochani, in North Macedonia (Latitude//longitude of location $1: 41^{\circ} 54^{\prime} 3.82^{\prime \prime} \mathrm{N}, 2^{\circ} 22^{\prime} 1.34$ 'E; location $2: 41^{\circ} 54^{\prime} 14.80^{\prime \prime} \mathrm{N}, 22^{\circ} 24^{\prime} 55.47^{\prime \prime} \mathrm{E}$; location $3: 41^{\circ} 53^{\prime} 26.74$ 'N, 


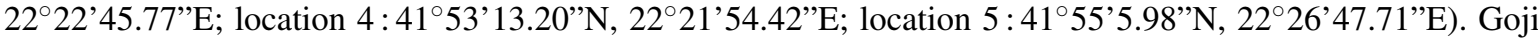
cultivation started in this area in 2012. Amounts of 2-3 kg fruits from 5-7 plants were sampled in the same day from the top, central and bottom part of the plant. Fresh fruits were transported to the laboratory in polypropylene bags. Fruits were air-dried in a convective dryer Memert UFE-500 (Buchenbach, Germany) at $60^{\circ} \mathrm{C}$ for $24 \mathrm{~h}$ to constant weight as described in [13]. Dried fruits were ground in a laboratory mill, sieved $(<250 \mu \mathrm{m})$ and stored in closed vials at $4^{\circ} \mathrm{C}$ until analysis. The reference sample was berries of Lycium chinense $\mathrm{M}$. variety, purchased in Beijing, China, with guarantee of authenticity. It was subjected to a preliminary preparation similar to Lycium barbarum $\mathrm{L}$.

\subsection{Sample preparation and analysis}

\subsubsection{Determination of TCC and sugar profile}

The phenol/sulfuric method of Dubois et al. [29] adapted by Skenderidis et al. [15, 30] for goji berry was used for the determination of TCC. Amounts of $0.25 \mathrm{~g}$ dried goji berry were subjected to ultrasound-assisted extraction in $5 \mathrm{~mL}$ water for $1 \mathrm{~h}$ at $50^{\circ} \mathrm{C}$. The supernatant was separated by centrifugation for $20 \mathrm{~min}$ at $5000 \mathrm{rpm}$ and filtered $(0.45 \mu \mathrm{m}$ nylon membrane). An aliquot of $1 \mathrm{~mL}$ extract was diluted to $100 \mathrm{~mL}$ with water. Then $80-100 \mu \mathrm{L}$ were mixed with $0.5 \mathrm{~mL}$ of $4 \%(\mathrm{w} / \mathrm{w})$ phenol and $2.5 \mathrm{ml}$ of $95 \%(\mathrm{w} / \mathrm{w})$ sulfuric acid, diluted to $5 \mathrm{~mL}$ with water and incubated for $10 \mathrm{~min}$ at $90^{\circ} \mathrm{C}$. The optical density was measured at $490 \mathrm{~nm}$ with the T $80+$ Double beam spectrophotometer (PG Instruments Ltd., UK). The TCC was expressed in g D-glucose equivalents/kg dry weight (d.w.) based on a 6-point calibration curve $(0-10 \mathrm{mg} / \mathrm{L})$.

Glucose, fructose and sucrose were determined by thin-layer chromatography (TLC) using HPTLC Sil G 60 $(20 \times 10)$ plates (Merck, Darmstadt, Germany) with automatic applicator Linomat 5 and Camag TLC Scanner 3 (Camag, Mutternz, Switzerland) after 1:20 dilution of the aqueous extract with ethanol according to Farag [31]. Separation was achieved from $50 \mu \mathrm{L}$ sample by elution with chloroform:acetic acid:water $(6: 7: 1, \mathrm{v} / \mathrm{v} / \mathrm{v})$ mixture. The separated spots were visualized using a coloring reagent containing $2 \%(\mathrm{w} / \mathrm{v})$ diphenylamine, $2 \%$ $(\mathrm{w} / \mathrm{v})$ aniline in acetone and $10 \mathrm{~mL}$ of $85 \%(\mathrm{w} / \mathrm{w})$ phosphoric acid after $5-10 \mathrm{~min}$ heating at $100-105^{\circ} \mathrm{C}$. The ImageDecipher-TLC software version 2.0 (BioDit Global Technology) was used for measuring the spot areas. The 5-point calibration curves were generated from aliquots in the range 5-25 $\mu \mathrm{L}$ of $1.25 \mathrm{mg} / \mathrm{mL}$ sugar in ethanol and the results were expressed in ( $\mathrm{g} / \mathrm{kg}$ d.w.).

\subsubsection{Determination of mineral composition and proteins}

The concentrations of $\mathrm{Na}, \mathrm{Mg}, \mathrm{K}, \mathrm{Ca}, \mathrm{Mn}, \mathrm{Fe}, \mathrm{Cu}, \mathrm{Zn}, \mathrm{S}, \mathrm{P}$ and Mo were determined by inductively coupled plasma optical emission spectrometry (ICP-OES) using SPECTRO CIROSCCD instrument (Spectro, Kleve,

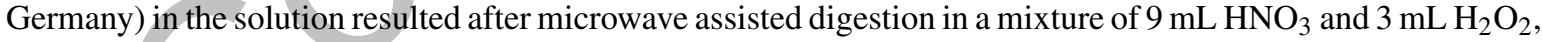
and diluted to $25 \mathrm{~mL}$. Determination of microelements ( $\mathrm{As}, \mathrm{Cd}, \mathrm{Cr}, \mathrm{Ni}, \mathrm{Pb}$ ) was carried out by graphite furnace atomic absorption spectrometry (GFAAS) with appropriate matrix modifier using the PinAAcle 900T Perkin Elmer spectrometer (Norwalk, CT, USA). Mercury was quantified on solid sample by thermal decomposition atomic absorption spectrometry (TDAAS) using the Automated Direct Mercury Analyzer Hydra-C (Teledyne Instruments, Leeman Labs, USA). An amount of $200 \mathrm{mg}$ solid sample was subjected to combustion in the furnace module, the generated $\mathrm{Hg}$ vapor was trapped in the amalgamator and $\mathrm{Hg}$ signal was measured as peak-area.

The protein content was estimated by indirect method based on nitrogen determination in solid sample (6.25 standard conversion factor) [32]. The nitrogen content was determined using a Flash EA $2000 \mathrm{CHNS} / \mathrm{O}$ analyzer from Thermo Fisher Scientific (Massachusetts, USA) by combustion of $2-3 \mathrm{mg}$ solid sample at $900^{\circ} \mathrm{C}$. The instrument calibration ( $\mathrm{K}$ factor method) was performed using atropine $(4.84 \% \mathrm{~N})$. The protein content was expressed as (\%) in dry mass. 


\subsubsection{Determination of FAs by GC-FID}

An amount of up to $2 \mathrm{~g}$ sample accurately weighed was subjected to extraction with $20 \mathrm{~mL} \mathrm{CHCl} / \mathrm{CH}_{3} \mathrm{OH}$ $(2: 1, \mathrm{v} / \mathrm{v})$ under mechanical shaking $(100 \mathrm{rpm})$ for $1 \mathrm{~h}$ at room temperature. The filtered extract was dried over anhydrous $\mathrm{Na}_{2} \mathrm{SO}_{4}$. After filtration, the organic extract was evaporated to dryness under a gentle $\mathrm{N}_{2}$ stream using Laborota 4010-DIGITAL rotary evaporator, Heidolph Instruments GmbH \& Co (Schwabach, Germany) and the resulted oil was stored at $4{ }^{\circ} \mathrm{C}$ until analysis. Base-catalyzed transmethylation was used for the conversion of fatty acid glycerides into the corresponding methyl esters, according to the SR EN ISO 5509: 2002 procedure. An aliquot of $50 \mathrm{mg}$ oil was dissolved in $4 \mathrm{~mL}$ isooctane in a test tube provided with ground glass stopper. Then $200 \mu \mathrm{L}$ of $2 \mathrm{~mol} / \mathrm{L}$ methanolic potassium hydroxide were added and the mixture was vigorously shaken for $30 \mathrm{~s}$. Further $1 \mathrm{~g} \mathrm{NaHSO} \mathrm{H}_{2} \mathrm{O}$ was added and the solution was vigorously shaken for $30 \mathrm{~s}$ [7, 8]. The analysis of methyl esters extracted in isooctane was achieved by gas chromatography-flame ionization detection (GC-FID) using Agilent 7890A GC System (Santa Clara, California, USA) with a split/splitless injector (split ratio of 1:50) and a DB-WAX fused silica capillary column $(30 \mathrm{~m} \times 0.32 \mathrm{~mm}$ i.d.) with a film thickness of $(0.25 \mu \mathrm{m})$. The FAMEs were identified by comparing the retention times in the chromatogram with those of a reference mixture of FAMEs (C8-C24 in isooctane). Individual FAMEs were quantified and the FAs profile was expressed in (\% w/w) of polyunsaturated (PUFA), monounsaturated (MUFA) and saturated (SFA) fatty acids. The PUFAs/SFAs ratio, artherogenic index (AI) and thrombogenic index (TI), oxidisability (Cox) and oxidative susceptibility (OS) were calculated [33, 34]:

$$
\begin{gathered}
A I=(4 \times C 14: 0+C 16: 0+C 18: 0) /\left(\sum M U F A+\sum \omega 6 P U F A+\sum \omega 3 P U F A\right) \\
T I=(C 14: 0+C 16: 0+C 18: 0) /(0.5 \times M U F A+0.5 \times \omega 6 P U F A+3 \times \omega 3 P U F A+(\omega 3 / \omega 6) P U F A)
\end{gathered}
$$

$$
\begin{gathered}
C_{o x}=(C 18: 1+10.3 \times C 18: 2+21.6 \times C 18: 3) / 100 \\
O S=M U F A+45 \times C 18: 2+100 \times C 18: 3
\end{gathered}
$$

\subsubsection{Determination of antioxidant activity, phenolic and carotenoid profiles}

Three assays, namely quenching of photochemical luminescence (PCL) of free superoxide anion radicals, DPPH (2,2-diphenyl-1-picrylhydrazyl) radical scavenging and ABTS ${ }^{\bullet+}$ (2,2'-Azino-bis-(3-ethylbenzthiazoline-sulphonic acid) radical scavenging were used to estimate antioxidant activity.

In the PCL assay, photochemiluminescence of free superoxide anion radicals was measured by optical excitation of a photosensitizer using the PHOTOCHEM device, Analytik Jena (Germany). Samples were prepared following the procedure recommended by the manufacturer. An aliquot of $300 \mathrm{mg}$ dried Goji berry was macerated overnight at $4{ }^{\circ} \mathrm{C}$ in $3 \mathrm{~mL}$ methanol then subjected to ultrasound-assisted extraction for $1 \mathrm{~h}$ at room temperature. The resulting suspension was centrifuged with Hettich Universal 320/320R Centrifuge (Tuttlingen, Germany) for $10 \mathrm{~min}$ at $3000 \mathrm{rpm}$ and the clear supernatant was analyzed. The antioxidant activity was expressed in TROLOX equivalents (mg TE/kg d.w.).

In the DPPH assay a volume of $290 \mu \mathrm{L}$ of $80 \mu \mathrm{mol} / \mathrm{L}$ ethanolic stock solution of DPPH was placed into a well of the multiplate, $10 \mu \mathrm{L}$ Goji berry extract were added then the sample was incubated for $30 \mathrm{~min}$. The absorbance was measured at $517 \mathrm{~nm}$ using a Tecan Spark 10M multiplate reader (Männedorf, Switzerland). The percentage

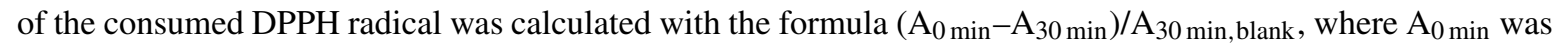

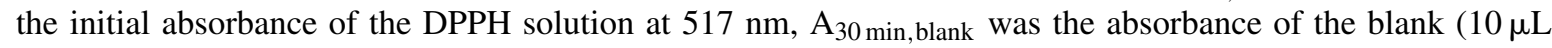
methanol added to DPPH solution) and $\mathrm{A}_{30 \mathrm{~min}}$ was the sample absorbance after 30 min incubation time. The results were expressed in quercetin equivalents (mg QE/kg d.w.) based on a 6-point calibration curve (0-25 $\mu \mathrm{g}$ $\mathrm{QE} / \mathrm{mL})$.

A similar protocol was followed in the $\mathrm{ABTS}^{\bullet+}$ radical scavenging assay, when $0.5 \mathrm{mmol} / \mathrm{L}$ radical $\mathrm{ABTS}^{\bullet+}$ solution was generated in phosphate buffer using ammonium persulfate. After 20 min reaction time the content 
of the bleached $\mathrm{ABTS}^{\bullet+}$ radical was evaluated at $734 \mathrm{~nm}$ using the multiplate reader. The result was expressed in gallic acid equivalents (mg GAE/kg d.w.) using a 7-point calibration curve ( $0-3 \mu \mathrm{g} \mathrm{GAE} / \mathrm{mL}$ ).

The TPC determined by the Folin-Ciocalteu method was expressed in mg GAE/kg d.w. [35]. An aliquot of $5 \mu \mathrm{L}$ of Goji berry extract was mixed with $225 \mu \mathrm{L}$ water and $20 \mu \mathrm{L}$ Folin-Ciocalteu reagent into a well of the multiplate and incubated in dark for $5 \mathrm{~min}$. Then, a volume of $50 \mu \mathrm{L}$ of $20 \%$ sodium carbonate solution was added and sample was incubated in dark for $30 \mathrm{~min}$. Seven calibration standards $(0-15 \mu \mathrm{g} \mathrm{GAE} / \mathrm{mL})$ were prepared similarly to Goji berry extracts. The absorbance of the deep-blue solutions was measured at $725 \mathrm{~nm}$ using a Tecan Spark $10 \mathrm{M}$ multiplate reader.

Individual polyphenols were quantified by high performance liquid chromatography with diode array detection (HPLC-DAD) on Shimadzu Nexera 1 system (Shimadzu Sci. Instrum., USA) using a Fortis C18 reversed-phase column $(150 \times 2.1 \mathrm{~mm}$ i.d., $3 \mu \mathrm{m}$ particle size) (Fortis Technologies Ltd., UK). The mobile phase consisted of water (80-10\%):0.1\% formic acid (10\%):acetonitrile (10-80\%). Total run time was $40 \mathrm{~min}$ at $1 \mathrm{~mL} / \mathrm{min}$ flow rate. Polyphenols were identified by comparing retention times in HPLC-DAD and UV/Vis absorption spectra with those of authentic standards, while their quantitation by linear calibration curves and measurement at specific wavelengths. The results were expressed as $\mathrm{mg}$ compound/kg d.w.

Carotenoids extraction was adapted from a protocol developed by Hempel et al. [17]. An aliquot of $0.25 \mathrm{~g}$ dried fruit was subjected to extraction in $5 \times 2 \mathrm{~mL}$ of a ternary mixture $(1: 1: 1 \mathrm{v} / \mathrm{v} / \mathrm{v})$ of methanol:ethyl acetate:light petroleum (b.p. $40-60^{\circ} \mathrm{C}$ ) by sonication for $30 \mathrm{~s}$. The combined extract separated by centrifugation (3000 rpm for $3 \mathrm{~min}$ ) was washed with water, the organic phase was dried with anhydrous $\mathrm{Na}_{2} \mathrm{SO}_{4}$ and then evaporated to dryness under an argon stream. The final residue was re-dissolved in $1 \mathrm{ml}$ ethyl acetate and stored at $-20^{\circ} \mathrm{C}$ until analysis. The determination of carotenoid profile was carried out by HPLC-DAD on Agilent 1200 system (Agilent Tehnologies, USA) using a reversed phase EC 250/4.6 Nucleodur 300-5 C-18 ec. column $(250 \times 4.6 \mathrm{~mm}$, $5 \mu \mathrm{m}$ particle size), (Macherey-Nagel, Germany). The mobile phase consisted of mixtures of acetonitrile:water $(9: 1, \mathrm{v} / \mathrm{v})$ with $0.25 \%(\mathrm{w} / \mathrm{v})$ triethylamine (A) and ethyl acetate with $0.25 \%(\mathrm{w} / \mathrm{v})$ triethylamine (B). The elution gradient was from $90 \%$ A to $50 \% \mathrm{~A}$ in $10 \mathrm{~min}$ and $10 \%$ in $20 \mathrm{~min}$ at $1 \mathrm{~mL} / \mathrm{min}$ flow rate. The chromatogram was registered at $450 \mathrm{~nm}$ and peaks were identified using carotenoid standards [36].

\subsection{Statistical analysis}

The examination of results and common statistics (correlation and regression) are not fully satisfactory for the characterization of superfoods. Multivariate unsupervised statistical approaches are more advanced tools for complex data interpretation to reveal hidden relationships between parameters and to put in evidence the influence of relevant characteristics on nutritional and functional properties of this food. Principal Component Analysis (PCA) was used to describe variability of chemical composition of berry of Lycium barbarum L. variety cultivated in North Macedonia and heat map to recognize the parameters significantly different from Lycium chinense M. The PCA provided the eigenvalues of the data correlation matrix, while Varimax rotation was used to maximize the variation expressed by the principal components (PCs). Only PCs with eigenvalue $>1$ were retained. For statistical analysis, non-detectable data for some components were substituted with half detection limit. The statistical analysis was carried out with Software Package Statistica 8.0 (StatSoft inc. 1984-2007, USA).

\section{Results and discussion}

\subsection{TCC, sugar profile and protein content}

Table 1 presents the content of sugars in berry of Lycium barbarum L. variety cultivated in North Macedonia in comparison with Lycium chinense M. The precisions of determinations for glucose, fructose and TCC $(n=3$ 
Table 1

Mean values for glucose, fructose, TCC (g/kg d.w.) and protein (\%) in Lycium barbarum L. berry cultivated in North Macedonia (samples 2-9) in comparison with Lycium chinense M.

\begin{tabular}{lcccc}
\hline Sample & Glucose (GLU) & Fructose (FRU) & TCC & Protein \\
\hline $1^{\mathrm{a}}$ & 252 & 233 & 463 & 3.5 \\
2 & 124 & 107 & 212 & 16.4 \\
3 & 220 & 163 & 370 & 11.0 \\
4 & 205 & 160 & 355 & 16.1 \\
5 & 195 & 130 & 330 & 15.5 \\
6 & 160 & 129 & 284 & 19.8 \\
7 & 181 & 128 & 296 & 15.5 \\
8 & 168 & 120 & 274 & 12.5 \\
9 & 174 & 102 & 295 & 20.3 \\
Min $(2-9)$ & 124 & 102 & 212 & 11.0 \\
Max $(2-9)$ & 220 & 163 & 370 & 20.3 \\
Mean \pm CI $(2-9)^{\mathrm{b}}$ & $178 \pm 25$ & $130 \pm 18$ & $302 \pm 42$ & $15.9 \pm 2.7$ \\
\hline
\end{tabular}

${ }^{\mathrm{a}}$ Lycium chinense M., dry fruit commercially available in China taken for comparison. ${ }^{\mathrm{b}}$ Confidence interval $(95 \%, n=8)$.

parallel measurements) were in the range $2-8 \%$, while for total protein of $4.4-14.2 \%$. The analysis of a Tomato leaves reference material (SRM 1573) used for method validation for protein content provided 98.9-100.0\% recovery $(n=3)$.

According to data in Table 1, TCC in Lycium barbarum L. variety cultivated in North Macedonia was in the range $212-370 \mathrm{~g} / \mathrm{kg}$. Glucose and fructose were found in large quantities, $124-220 \mathrm{~g} / \mathrm{kg}$ and $102-163 \mathrm{~g} / \mathrm{kg}$ respectively, while sucrose was below the detection limit in HPTLC $(10 \mathrm{~g} / \mathrm{kg})$. All values were found to be significantly lower than in the Lycium chinense $\mathrm{M}$. variety for $95 \%$ confidence level. Sugar profile dominated by glucose $(152.92-284.60 \mathrm{~g} / \mathrm{kg})$ and fructose $(154.20-259.13 \mathrm{~g} / \mathrm{kg})$, and low sucrose content $(13.75-36.43 \mathrm{~g} / \mathrm{kg})$ were reported by Montesano et al. [14] in dry fruit of Lycium barbarum L. marketed in China, and Zheng et al. [37] in Lycium barbarum L. and Lycium chinense M. varieties cultivated in different regions in China. Zheng et al. noticed also that enrichment in glucose and fructose from 50 to $250 \mathrm{~g} / \mathrm{kg} \mathrm{d}$.w. and decrease of sucrose from 50 to $10 \mathrm{~g} / \mathrm{kg}$ d.w. fruit occurred during the 24-34 days after blossom. Moreover, environmental conditions such as temperature, light, water, soil factors $\left(\mathrm{HCO}_{3}{ }^{-}, \mathrm{Na}^{+}, \mathrm{K}^{+}, \mathrm{Ca}^{2+}, \mathrm{Mg}^{2+}, \mathrm{Cl}^{-}\right.$, total salt, $\mathrm{pH}$, organic matter and available nitrogen) affect sugar content. The influence of these parameters was not examined within our study, however we noticed lower values for TCC, glucose and fructose in Lycium barbarum L. cultivated in North Macedonia than in the same variety coming from China, Mongolia [14, 37] and Greece [15]. Data in Table 1 for Lycium barbarum L. reveal differences in terms of TCC and individual sugars respectively, possibly due to different ripening stages as also remarked for Lycium barbarum L. and Lycium chinense M. cultivated in China, Mongolia and Greece [14, 15, 37]. In samples of Lycium barbarum L. analyzed by us higher values for TCC (330-370 g/kg d.w.), glucose (195-220 g/kg d.w.) and fructose (130-163 g/kg d.w.) corresponded to samples 3-5 collected in August. Skenderidis et al. [15] found also higher TCC in berries of Lycium chinense M. $(440 \pm 5.2 \mathrm{~g} / \mathrm{kg})$ and Lycium barbarum L. $(490 \pm 6.8 \mathrm{~g} / \mathrm{kg})$ cultivated in Greece and collected in August.

A daily serving of $30 \mathrm{~g}$ Goji berry of Lycium barbarum L. from North Macedonia would provide $10.0 \pm 2.1 \%$ RDA protein for adults ( $0.8 \mathrm{~g} / \mathrm{kg}$ b. w.) [38], significantly more than Lycium chinense M. Its nutritional significance is related to indispensable aminoacids such as histidine, isoleucine, leucine, lysine, methionine, phenylalanine, threonine in goji berry [39]. 
Table 2

Results obtained in elemental analysis of Lycium barbarum L. berry cultivated in North Macedonia (samples 2-9) in comparison with Lycium chinense $\mathrm{M}$.

\begin{tabular}{lcccccccccccccccccc}
\hline Sample & \multicolumn{11}{c|}{ Concentration in mg/kg for $n=3$ parallel measurements } \\
\cline { 2 - 3 } & $\mathrm{Na}$ & $\mathrm{Mg}$ & $\mathrm{K}$ & $\mathrm{Ca}$ & $\mathrm{Mn}$ & $\mathrm{Fe}$ & $\mathrm{Cu}$ & $\mathrm{Zn}$ & $\mathrm{P}$ & $\mathrm{S}$ & $\mathrm{Cr}$ & $\mathrm{Mo}$ & $\mathrm{As}$ & $\mathrm{Pb}$ & $\mathrm{Cd}$ & $\mathrm{Ni}$ & $\mathrm{Hg}$ \\
\hline $1^{\mathrm{a}}$ & 4140 & 826 & 13020 & 651 & 9.66 & 34.6 & 8.00 & 12.1 & 1695 & 257 & 0.660 & $<0.5$ & 0.017 & $<0.020$ & 0.024 & 2.720 & 0.011 \\
2 & 4630 & 1170 & 24200 & 735 & 16.7 & 71.9 & 11.1 & 23.5 & 3560 & 325 & 0.570 & $<0.5$ & 0.015 & $<0.020$ & 0.167 & 1.040 & 0.005 \\
3 & 1660 & 1180 & 22000 & 567 & 15.8 & 76.9 & 10.3 & 18.0 & 3715 & 222 & 0.860 & $<0.5$ & $<0.006$ & $<0.020$ & 0.100 & 8.820 & 0.006 \\
4 & 6240 & 1310 & 17600 & 663 & 20.2 & 58.3 & 11.3 & 21.2 & 4935 & 236 & $<0.015$ & $<0.5$ & 0.018 & 0.211 & $<0.004$ & 0.096 & 0.010 \\
5 & 3530 & 1200 & 18400 & 844 & 19.4 & 58.8 & 11.8 & 22.3 & 3865 & 214 & $<0.015$ & $<0.5$ & 0.013 & 0.196 & $<0.004$ & $<0.025$ & $<0.004$ \\
6 & 2940 & 1190 & 26000 & 920 & 16.9 & 51.5 & 10.5 & 21.4 & 4010 & 315 & 0.026 & $<0.5$ & $<0.006$ & 0.036 & 0.014 & $<0.025$ & $<0.004$ \\
7 & 3020 & 1390 & 28100 & 1010 & 20.5 & 67.6 & 12.4 & 26.0 & 4865 & 445 & $<0.015$ & $<0.5$ & $<0.006$ & $<0.020$ & 0.014 & $<0.025$ & $<0.004$ \\
8 & 3340 & 1100 & 24100 & 841 & 16.1 & 69.4 & 10.3 & 20.1 & 3570 & 260 & 0.250 & $<0.5$ & 0.014 & $<0.020$ & $<0.004$ & $<0.025$ & 0.005 \\
9 & 3650 & 1225 & 22100 & 769 & 12.0 & 57.6 & 12.4 & 18.9 & 4145 & 296 & $<0.015$ & $<0.5$ & $<0.006$ & $<0.020$ & 0.057 & $<0.025$ & 0.006 \\
Min (2-9) & 1660 & 1100 & 17600 & 567 & 12.0 & 51.5 & 10.3 & 18.0 & 3560 & 214 & 0.015 & & 0.006 & 0.020 & 0.004 & 0.025 & 0.004 \\
Max (2-9) & 6240 & 1390 & 28100 & 1010 & 20.5 & 76.9 & 12.4 & 26.0 & 4935 & 445 & 0.860 & & 0.018 & 0.211 & 0.167 & 8.820 & 0.010 \\
Mean (2-9) & 3626 & 1221 & 22813 & 794 & 17.2 & 64.0 & 11.3 & 21.4 & 4083 & 289 & 0.221 & & 0.011 & 0.068 & 0.046 & 1.260 & 0.006 \\
CI (2-9)b & 1124 & 75 & 2990 & 118 & 2,3 & 7.3 & 0.8 & 2.2 & 454 & 64 & 0,272 & & 0.004 & 0.007 & 0.050 & 2.571 & 0.002 \\
\hline
\end{tabular}

${ }^{\mathrm{a}}$ Lycium chinense M., dry fruit commercially available in China taken for comparison. ${ }^{\mathrm{b}}$ Confidence interval $(95 \%, n=8)$.

\subsection{Elemental composition}

The concentrations of the selected elements in dried Goji berry are presented in Table 2. Precision of measurements $(n=3)$ for $\mathrm{Na}, \mathrm{Mg}, \mathrm{K}, \mathrm{Ca}, \mathrm{Mn}, \mathrm{Fe}, \mathrm{Cu}, \mathrm{Zn}, \mathrm{S}$ and $\mathrm{P}$ in ICP-OES was $2.5-13.6 \%$, for $\mathrm{As}, \mathrm{Cr}, \mathrm{Pb}, \mathrm{Cd}$ and Ni by GFAAS of $4.0-12.1 \%$ and $\mathrm{Hg}$ by TDAAS in the range $7.7-15.4 \%$. Methods were assessed by analyzing certified reference materials of fruits and vegetables that provided recoveries of $87-108 \%$.

Concentrations of $\mathrm{K}, \mathrm{Mn}, \mathrm{Fe}, \mathrm{Zn}$ and $\mathrm{P}$ were up to 2 times greater, while $\mathrm{Cr}$ was two times lower in Lycium barbarum L. compared to Lycium chinense $\mathrm{M}$. under study. The decreasing order of mean concentrations of elements in Lycium barbarum L. berry cultivated in North Macedonia was $K>\mathrm{P}>\mathrm{Na}>\mathrm{Mg}>\mathrm{Ca}>\mathrm{S}>\mathrm{Fe}>$ $\mathrm{Zn}>\mathrm{Mn}>\mathrm{Cu}>\mathrm{Cr}$, similar to that reported by other authors, however with differences in terms of content as a result of the influence of local conditions $[4,9,16,40]$. Thus similar concentrations were found for $\mathrm{K}, \mathrm{Mg}$ and $\mathrm{Ca}$ and higher for $\mathrm{Na}$ and $\mathrm{P}$ in Lycium barbarum L. berry cultivated in North Macedonia compared to the same variety cultivated in Italy [16]. Higher concentrations of $\mathrm{K}$ and $\mathrm{P}$ and much lower for Na were found in our samples compared to Lycium barbarum L. cultivated in Asia [16].

According to Regulation (EU) No. 1169/2011 a value of at least 15\% RDA supplied per single portion should be considered a significant intake for minerals and micronutrients, while below 5\% it is rather modest [41].

The \%RDA contributions from a daily serving of $30 \mathrm{~g}$ of dried Goji berry are presented in Table 3 .

The results reflect a higher contribution to the diet of Lycium barbarum L. compared to Lycium chinense M. Values of \%RDA were higher than $15 \%$ for 4 elements, namely $34 \%$ for $\mathrm{K}$ and $\mathrm{Cu}, 26 \%$ for $\mathrm{Mn}$ and $18 \%$ for $P$. Values for $\mathrm{Zn}, \mathrm{Mg}$ and $\mathrm{Fe}$ were in the range 6-14\%, while for Ca below 5\%. Molybdenum was not taken into consideration, since it could not be quantified by ICP-OES in any of samples. The contribution of $\mathrm{Cr}$ to diet was difficult to evaluate as in half of samples it was below the detection limit in GFAAS, which resulted in a large dispersion of \%RDA $(16.8 \pm 20.4 \%)$. The same observation was made by Llorent-Martinez et al. [4].

Goji fruit has been often referred to as supply for several minerals. Kafkaletou et al. [10] found berry of Goji cultivated in Greece a significant source of K irrespective of variety. Niro et al. [13] has declared dried Goji berries as a great source of $\mathrm{Cu}, \mathrm{K}, \mathrm{P}, \mathrm{Fe}$ and $\mathrm{Zn}$, since a daily consumption of $30 \mathrm{~g}$ provides an intake of approximately 
Table 3

Percentage contribution to the RDA of minerals for daily serving of $30 \mathrm{~g}$ of dried Goji berry related to Regulation (EU) No. $1169 / 2011$

\begin{tabular}{lccccccccc}
\hline Sample & \multicolumn{1}{c}{ Nutrient } & \multicolumn{1}{c}{} \\
\cline { 2 - 9 } & $\mathrm{K}$ & $\mathrm{Cu}$ & $\mathrm{Mn}$ & $\mathrm{P}$ & $\mathrm{Fe}$ & $\mathrm{Mg}$ & $\mathrm{Zn}$ & $\mathrm{Ca}$ & $\mathrm{Cr}$ \\
\hline RDA/mg/day (EU 1169/2011) & 2000 & 1 & 2 & 700 & 14 & 375 & 10 & 800 & 0.04 \\
\%RDA Lycium chinense M. & 19.5 & 24.0 & 14.6 & 7.2 & 7.4 & 6.6 & 3.6 & 2.4 & 49.5 \\
\%RDA \pm C.I. Lycium barbarum & $34.2 \pm 4.5$ & $33.8 \pm 2.2$ & $25.8 \pm 3.5$ & $17.5 \pm 2.3$ & $13.7 \pm 1.6$ & $9.8 \pm 0.6$ & $6.4 \pm 0.8$ & $3.0 \pm 0.4$ & $16.6 \pm 20.4$ \\
L. (North Macedonia) & & & & & & & & \\
\hline
\end{tabular}

25\%RDA for $\mathrm{Cu}, 13 \% \mathrm{~K}$ and between 5-10\% for the rest of elements. Also, according to Bertoldi et al. [16], Italian Goji berries are a rich source of elements, since a daily portion of $28 \mathrm{~g}$ provides $20 \% \mathrm{RDA}$ for $\mathrm{Cu}, 15 \%$ Mo, 8-17\% Fe, 7-13\% Cr, 10-12\% Mn, 6-9\% Mg, P, K, Na, 3-4\% Zn and 1-2\% Ca and Se. In a speciation study Wojcieszek et al. [42] have found trace metals from berries of Lycium barbarum L. highly bioaccessible to human body, about $56 \% \mathrm{Mn}, 72 \% \mathrm{Cu}, 64 \% \mathrm{Zn}$ in the gastric extract and approximately $35 \% \mathrm{Mn}, 25 \% \mathrm{Cu}$ and $31 \% \mathrm{Zn}$ in the gastrointestinal extract.

In terms of elements with potential risk to human health, $\mathrm{Ni}, \mathrm{Pb}, \mathrm{Cd}$ and $\mathrm{As}$ in Macedonian Goji berry had similar concentrations to Goji berry marketed in Spain [4] and Poland [9] and Hg was lower than in Italian Goji [16]. Commission Regulation (EC) No. 1881/2006 [43] sets maximum levels in fresh small fruits only for Cd and $\mathrm{Pb}$. Since we performed analysis on dried fruits it was found more useful to assess exposure risk in connection with the Provisional Tolerable Weekly Intake (PTWI) ( $\mu \mathrm{g} / \mathrm{kg}$ b.w.) of 7 (Cd), $25(\mathrm{~Pb}), 3(\mathrm{As})$ and $5(\mathrm{Hg})$ [44]. Thus a daily serving of $30 \mathrm{~g}$ dried Macedonian Goji berries results in an intake of less than $8 \% \mathrm{Cd}, 3 \% \mathrm{~Pb}, 2 \%$ As and $1 \% \mathrm{Hg}$ posing no risk of exposure for an adult of $60 \mathrm{~kg}$. Total Target Hazard Quotient (TTHQ) coming from $\mathrm{Cd}, \mathrm{As}, \mathrm{Hg}, \mathrm{Pb}$ and $\mathrm{Ni}$ was calculated to assess the non-carcinogenic risk. The calculus was based on $30 \mathrm{~g}$ per day ingested dried Macedonian Goji berry, 365 days per year exposure frequency, $60 \mathrm{~kg}$ average b.w., 70 exposure years and oral reference doses (RfDs) in $\mu \mathrm{g} / \mathrm{kg}$ per day of $1(\mathrm{Cd}), 0.3(\mathrm{As}), 0.3(\mathrm{Hg}), 4(\mathrm{~Pb})$ and $20(\mathrm{Ni})$ [45]. The resulted TTHQ of $0.087 \pm 0.036$ (95\% confidence level), similar to 0.122 for Lycium chinense M. is much lower than 1, so that the exposed population is unlikely to experience any adverse health hazard. Bertoldi et al. [16] also reported no risk exposure through consumption of Italian Goji. The observation is of concern especially for vegetarians.

\subsection{Fatty acids profile}

The FAs composition in oil is summarized in Table 4. The crude lipid content of $12.2 \pm 1.2 \%$ in dried Lycium barbarum L. berry from North Macedonia was significantly higher $(p<0.05)$ that in Lycium chinense M. $(8.2 \%)$. Precision in GC-FID was in the range $5-10 \%$ ( $n=3$ parallel measurements).

Twelve fatty acids were identified with chain lengths from C8 to C24. The erucic (C22:1n-9) and lignoceric (C24:0) acids were not detected in any sample. The lipid profile was dominated by PUFAs $(69.23 \pm 2.30 \%)$, principally due to the presence of linoleic acid (C18:2n-6, $67.64 \pm 2.41 \%)$, followed by SFAs $(16.62 \pm 2.23 \%)$ with palmitic acid $(\mathrm{C} 16: 0,10.51 \pm 1.16 \%)$ and stearic acid $(\mathrm{C} 18: 0,3.49 \pm 0.31 \%)$ as majors, and MUFAs $(14.15 \pm 0.77 \%)$ with oleic acid $(\mathrm{C} 18: 1 \mathrm{n}-9,14.02 \pm 0.75 \%)$ as major contributor. The individual percentages of the other FAs were below $1 \%$ excepting linolenic acid $(\mathrm{C} 18: 3 \mathrm{n}-3,1.59 \pm 1.07 \%)$ and arachidic acid (C20:0, $1.12 \pm 0.33 \%)$. The $t$-test emphasized a significant lower content of $\Sigma$ SPAs, $\Sigma$ MUFAs and higher content of $\Sigma$ PUFAs in crude oil from Lycium barbarum L. berries cultivated in North Macedonia than in Lycium chinense M. $(p<0.05)$. The significant higher content of $\Sigma$ PUFAs is determined by the linoleic acid, while the lower content of $\Sigma$ MUFAs and $\Sigma$ SPAs is the result of lower content of oleic and stearic acids $(p<0.05)$. There was no significant difference between the two varieties in terms of palmitic acid. 
Table 4

Fatty acids profile (\%,w/w) in oil of Lycium barbarum L. berry cultivated in North Macedonia (samples 2-9) in comparison with Lycium chinense M.

\begin{tabular}{|c|c|c|c|c|c|c|c|c|c|c|c|c|c|c|c|c|}
\hline Sample & $\begin{array}{c}\text { Lipid } \\
(\%, w / w)\end{array}$ & $\begin{array}{c}\text { C8:0 } \\
\text { Caprylic }\end{array}$ & $\begin{array}{l}\text { C10:0 } \\
\text { Capric }\end{array}$ & $\begin{array}{l}\text { C12:0 } \\
\text { Lauric }\end{array}$ & $\begin{array}{c}\text { C14:0 } \\
\text { Myristic }\end{array}$ & $\begin{array}{c}\text { C16:0 } \\
\text { Palmitic }\end{array}$ & $\begin{array}{c}\text { C16:1 } \\
\text { Palmitoleic }\end{array}$ & $\begin{array}{l}\text { C18:0 } \\
\text { Stearic }\end{array}$ & $\begin{array}{c}\text { C18: } \ln 9 \\
\text { Oleic }\end{array}$ & $\begin{array}{l}\text { C18:2n6 } \\
\text { Linoleic }\end{array}$ & $\begin{array}{l}\text { C18:3n3 } \\
\text { Linolenic }\end{array}$ & $\begin{array}{c}\text { C20:0 } \\
\text { Arachidic }\end{array}$ & $\begin{array}{c}\text { C22:0 } \\
\text { Behenic }\end{array}$ & $\Sigma$ SFAs & $\Sigma$ MUFAs & $\Sigma$ PUFAs \\
\hline $1^{\mathrm{a}}$ & 8.2 & 0.99 & 0.85 & 0.81 & 0.08 & 9.93 & 0.19 & 4.00 & 18.10 & 59.22 & 3.00 & 1.59 & 1.26 & 19.50 & 18.29 & 62.22 \\
\hline 2 & 13.4 & 0.73 & 0.26 & $<0.011$ & 0.16 & 11.79 & $<0.005$ & 2.87 & 13.35 & 67.26 & 2.05 & 1.54 & $<0.002$ & 17.35 & 13.35 & 69.31 \\
\hline 3 & 13.8 & 0.09 & 0.09 & 0.09 & 0.11 & 8.31 & 0.20 & 3.41 & 15.23 & 70.98 & 0.40 & 0.86 & 0.24 & 13.19 & 15.43 & 71.38 \\
\hline 4 & 12.2 & 0.09 & 0.08 & 0.06 & 0.10 & 8.43 & 0.25 & 3.40 & 12.75 & 70.45 & 3.53 & 0.68 & 0.18 & 13.02 & 13.00 & 73.98 \\
\hline 5 & 13.1 & 1.23 & $<0.012$ & 1.28 & 0.12 & 11.67 & $<0.005$ & 3.75 & 13.88 & 65.01 & 1.61 & 1.40 & 0.05 & 19.50 & 13.88 & 66.62 \\
\hline 6 & 10.4 & 0.05 & 0.21 & 0.21 & 0.19 & 10.70 & 0.32 & & 15.03 & 68.96 & 0.32 & 0.59 & 0.08 & 15.37 & 15.35 & 69.28 \\
\hline 7 & 13.5 & 1.06 & 1.16 & 0.84 & 0.10 & 11.36 & & 3.71 & 14.29 & 64.98 & 0.93 & 1.52 & 0.01 & 19.76 & 14.33 & 65.91 \\
\hline 8 & 10.9 & 1.23 & 0.65 & $<0.011$ & 0.12 & 11.21 & 20005 & 4.13 & 14.48 & 63.43 & 3.32 & 1.43 & $<0.002$ & 18.77 & 14.48 & 66.75 \\
\hline 9 & 10.7 & 0.39 & 0.27 & 0.29 & 0.09 & 10.64 & 0.20 & 3.34 & 13.16 & 70.03 & 0.58 & 0.91 & 0.09 & 16.02 & 13.36 & 70.61 \\
\hline $\operatorname{Min}(2-9)$ & 10.4 & 0.05 & $<0.012$ & $<0.011$ & 0.09 & & $<0.005$ & 2.87 & 12.75 & 63.43 & 0.04 & 0.59 & $<0.002$ & 13.02 & 13.00 & 65.91 \\
\hline $\operatorname{Max}(2-9)$ & 13.8 & 1.23 & 1.16 & 1.28 & 0.19 & 11.79 & 0.32 & 4.13 & 15.23 & 70.98 & 3.53 & 1.54 & 0.24 & 19.76 & 15.43 & 73.98 \\
\hline Mean (2-9) & 12.2 & 0.61 & 0.39 & 0.46 & 0.12 & 10.51 & 0.20 & 3.49 & 14.02 & 67.64 & 1.59 & 1.12 & 0.11 & 16.62 & 14.15 & 69.23 \\
\hline CI $(2-9)^{\mathrm{b}}$ & 1.2 & 0.43 & 0.32 & 0.41 & 0.03 & 1.16 & 0.09 & 0.31 & 0.75 & 2.41 & 1.07 & 0.33 & 0.07 & 2.23 & 0.77 & 2.30 \\
\hline
\end{tabular}

${ }^{\mathrm{a}}$ Oil extracted from Lycium chinense M. (dried fruits). ${ }^{\mathrm{b}}$ Confidence interval $(95 \%, n=8)$. 
Compared to Goji cultivated in other European (Italy, Portugal and Greece) or Asiatic (China, Mongolia) countries the FAs profile of Lycium barbarums L. cultivated in North Macedonia is significantly different in terms of unsaturated acids $[7,8,15,46]$. Thus, PUFAs was higher than in berries coming from Italy $(48.4 \%)$, Portugal (56.8\%), Greece (48.54-51.11\%), China (44.35; 64.2\%) or Mongolia (47.59; 62.3\%). On the other side, the content of total unsaturated fatty acids $($ UFAs) $=\Sigma$ PUFAs $+\Sigma$ MUFAs $(83.4 \pm 2.4 \%)$ in the Macedonian goji oil was higher than that reported for oil of Portugal goji (74.0\%) and similar to that of Italian origin (78.0-86.0\%), China (70.54/85.8\%) and Mongolia (73.42/82.0\%). Obviously, FAs profile is depending on local conditions and could be used to discriminate the geographical origin of Lycium barbarum L. berry as stated by Cossignani et al. [7].

The lipid indices of oil from Lycium barbarum L. cultivated in North Macedonia compared to Lycium chinense M. and other vegetable oils are presented in Table 5.

Data in Table 5 emphasize the strong influence of FAs profile in vegetable oils on lipid indices. For health benefits PUFAs/SFAs ratio should be at least $0.4-0.5, \mathrm{n}-3 / \mathrm{n}-6$ ratio at least $0.2-0.25$, AI, TI, oxidisability value (Cox) as low as possible, while oxidative susceptibility (OS) as high as possible [33, 47,48]. Thus, high values of PUFAs/SFAs ratio (4.29 \pm 0.74$)$ and oxidative susceptibility (OS) (3217 \pm 125$)$, as well as the low values for AI $(0.13 \pm 0.02)$ and TI $(0.31 \pm 0.04)$ in Macedonian Lycium barbarum L. oil demonstrate its benefits for health of cardiovascular system. On the other side, the $n-3 / n-6$ ratio $(0.024 \pm 0.016)$ was below the trash of 0.2 for healthy food. The reason was that linolenic acid (C18:3n-3) was the single n-3 PUFA identified in oil and it could not balance the major n-6 PUFAs. It was found that the content of n-3 PUFA is strongly dependent on maturation stage and drops significantly at maturity of fruit and seed [55]. A low n-3/n-6 ratio is characteristic for vegetable oils, some of them taken for comparison in Table 5. The oil of Macedonian Lycium barbarum L. has comparable stability to other vegetable oils in terms of $\mathrm{C} 18$ unsaturated fatty acids oxidation excepting olive and pumpkin seed oils. These oils are less prone to oxidation (lower Cox) consistent with the much lower PUFAs/MUFAs ratio. The lipid indices of Lycium barbarum L. berry oil are similar to Lycium chinense $\mathrm{M}$. and Italian Goji seed oil extracted from Lycium barbarum L. Overall, Lycium barbarum L. berry and related oil represent a dietary source of essential FAs with anti-atherogenic and anti-thrombogenic effects.

\subsection{Antioxidant capacity. Polyphenol and carotenoid profiles}

Antioxidant activity, polyphenol and carotenoid profiles determined by PCL, DPPH and ABTS methods are presented in Table 6. Precision of measurements was 3.0-8.5\%; $2.5-7.5 \% ; 3.5-9.2 \%$ for antioxidant activity in the PCL, DPPH and ABTS methods, $2.5-9.2 \%$ for individual carotenoids and 3.5-8.5\% for TPC and individual polyphenols.

The average antioxidant activity of Lycium barbarum L. berry extracts was about half that in Lycium chinense M. variety. The antioxidant activity measured by PCL method was $2037 \pm 1084 \mathrm{mg}$ TE/kg.

The TPC of $5906 \pm 1262 \mathrm{mg} \mathrm{GAE} / \mathrm{kg}$ in Macedonian Goji berry was not significantly different from $6220 \mathrm{mg}$ GAE/kg in Lycium chinense M. ( $p>0.05)$. TPC in Goji of Macedonian origin was lower than in selected Goji cultivars in Romania (11600-15700 mg GAE/kg) [12], higher than in Goji cultivars in Switzerland (710-2940 mg GAE $/ \mathrm{kg}$ ) [11] and Italian Goji (7600 mg GAE/kg) [49]. The differences could be attributed to ecophysiological conditions, altitude and soil composition. Polyphenol profile in Macedonian Goji berry is dominated by anthocyanins, namely delphinidin-3-o-rutoside $(880 \pm 184 \mathrm{mg} / \mathrm{kg})$, while the salicylic acid prevailed among phenolic acids $(875 \pm 271 \mathrm{mg} / \mathrm{kg})$. Amounts of $14 \pm 6 \mathrm{mg} / \mathrm{kg}$ ellagic acid, $9 \pm 4 \mathrm{mg} / \mathrm{kg}$ ferulic acid and $28 \pm 8 \mathrm{mg} / \mathrm{kg}$ cinnamic acid were also quantified.

A number of 6 specific caretonoids responsible for the pigment profile of goji berries were quantified by HPLCDAD: 3 free xantophills, namely (all-E)-lutein (LU), (all-E)-zeaxanthin (ZE), (all-E)- $\beta$-carotene (bCR) and 3 esterified-xantophills, namely (all-E)-antheraxanthin dipalmitate (ATD), (all-E)-zeaxanthin myristate palmitate (ZMP) and (all-E)-zeaxanthin dipalmitate (ZD). The significant variability in carotenoid profile is related to different degree of berry ripeness, as also observed by Hempel et al. [11]. Thus, specific free carotenoids for 
Table 5

Lipid indices in oil of Lycium barbarum L. from North Macedonia compared to Lycium chinense M. and other vegetable oils

\begin{tabular}{|c|c|c|c|c|c|c|c|c|c|}
\hline Sample & PUFAs/SFAs & PUFAs/MUFAs & $n-3^{b}$ & $n-6^{b}$ & $\mathrm{n}-3 / \mathrm{n}-6$ & AI & TI & Cox & OS \\
\hline Lycium chinense $\mathrm{M}$. oil & 3.19 & 3.40 & 3.00 & 59.22 & 0.050 & 0.13 & 0.29 & 6.93 & 2983 \\
\hline Lycium barbarum L. (North Macedonia) oil ${ }^{\mathrm{a}}$ & $4.29 \pm 0.74$ & $4.91 \pm 0.36$ & $1.59 \pm 1.07$ & $67.64 \pm 2.41$ & $0.024 \pm 0.016$ & $0.13 \pm 0.02$ & $0.31 \pm 0.04$ & $7.45 \pm 0.28$ & $3217 \pm 125$ \\
\hline Italian Goji seed oil (Lycium barbarum L) [49] & $4.18(4.1)$ & $1.43(1.4)$ & 1.6 & 49.94 & 0.032 & 0.1 & 0.2 & 5.98 & 2512 \\
\hline Brazilian Soybean oil [50] & $3.44-3.79$ & $2.09-2.47$ & $3.47-5.42$ & $51.29-53.80$ & $0.068-0.099$ & $0.14-0.15$ & $0.27-0.30$ & $6.41-6.94$ & 2744-2987 \\
\hline Algerian Virgine Olive oil [51] & $0.31-1.16$ & $0.22-0.65$ & $0.47-0.69$ & $4.95-12.65$ & $0.044-0.127$ & $0.26-0.48$ & $0.60-1.11$ & $1.37-2.43$ & $311-798$ \\
\hline Croatian Olive oil [52] & 0.64 & 0.14 & 0.7 & 9.4 & 0.074 & 0.15 & 0.35 & 1.85 & 567 \\
\hline Croatian Pumpkin seeds oil [52] & 2.82 & 1.62 & 0.2 & 50.30 & 0.004 & 0.16 & 0.42 & 5.54 & 2315 \\
\hline Patagonian Fresh Maqui [53] & 3.43 & 1.90 & 1.96 & 46.00 & 0.043 & 0.18 & 0.32 & 5.50 & 2291 \\
\hline Patagonian Dried Maqui [53] & 3.49 & 1.92 & 2.09 & 46.31 & 0.045 & 0.18 & 0.31 & 5.55 & 2318 \\
\hline Chinese Grape seed oil [54] & 6.18 & 2.66 & 2.94 & 64.11 & 0.046 & 0.07 & 0.20 & 7.46 & 3204 \\
\hline
\end{tabular}

${ }^{\mathrm{a}}$ Mean \pm C.I. $(95 \%, n=8) .{ }^{\mathrm{b}}$ Expressed in $\%(\mathrm{w} / \mathrm{w})$.

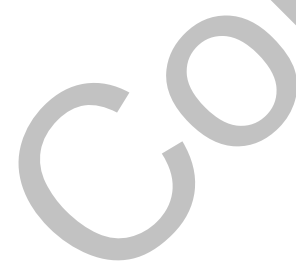


Table 6

Antioxidant activity, polyphenol and carotenoid profiles of Lycium barbarum L. berry cultivated in North Macedonia (samples 2-9) in comparison with Lycium chinense $\mathrm{M}$.

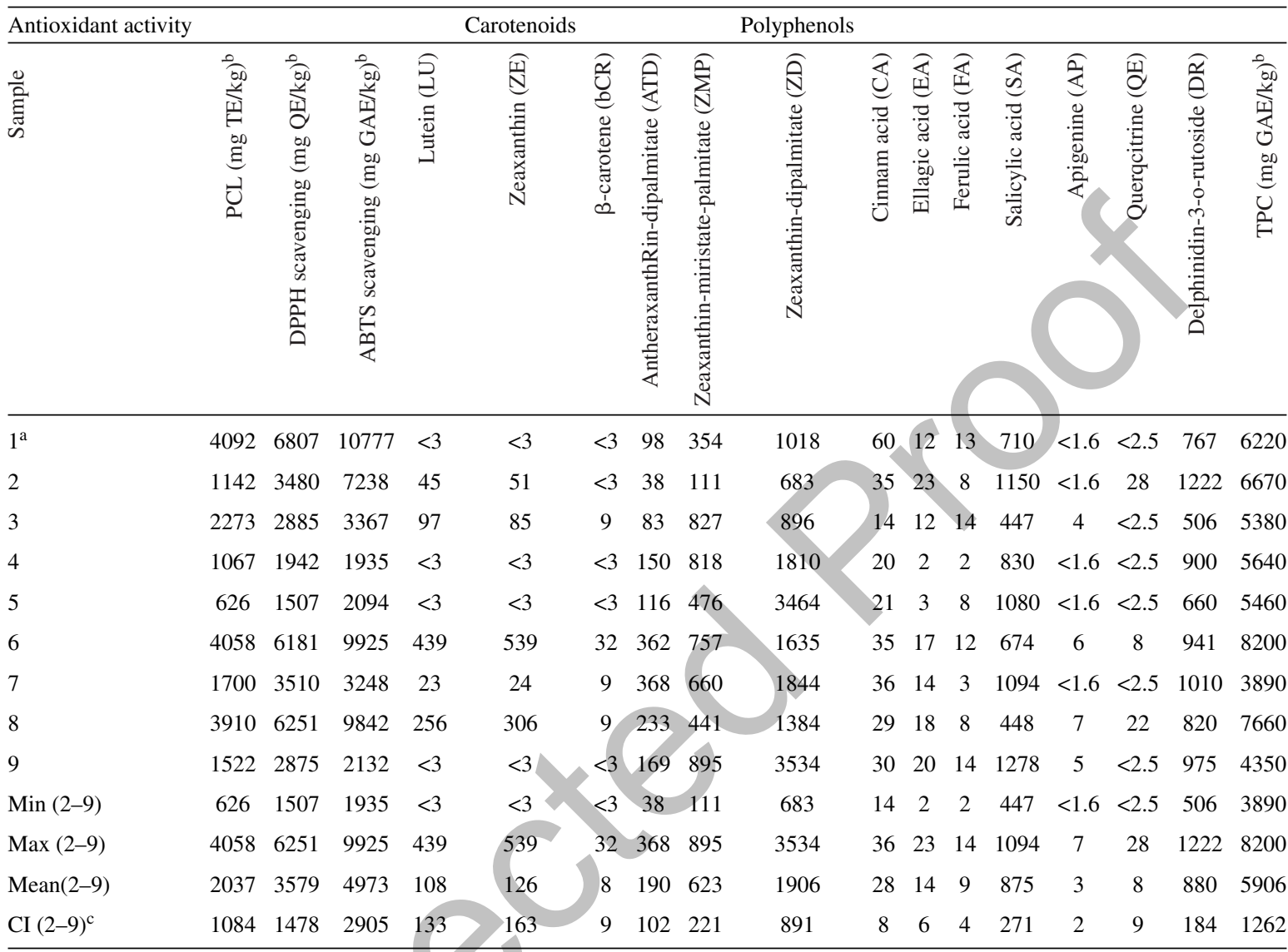

${ }^{\mathrm{a}}$ Lycium chinense M., dry fruit commercially available in China taken for comparison. ${ }^{\mathrm{b}}$ TROLOX equivalents; quercetin equivalents; gallic acid equivalents. ${ }^{c}$ Confidence interval $(95 \%, n=8)$.

unripe fruits or those that have not reached full ripeness, such as lutein, zeaxanthin and $\beta$-carotene, were found in higher amount in samples 6 and 8. Total carotenoids in Macedonian Goji berry considering all fruits irrespective of ripening stage were $2962 \pm 986 \mathrm{mg} / \mathrm{kg}$, significantly higher than $1475 \mathrm{mg} / \mathrm{kg}$ in Lycium chinense M. variety, and $1978 \mathrm{mk} / \mathrm{kg}$ in the Asian Goji berry (Lycium barbarum L.) [16]. Considering only berries that reached full ripening $(4,5,7,9)$, total carotenoids were $3593 \pm 1404 \mathrm{mg} / \mathrm{kg}$, similar to Italian goji berries (Lycium barbarum L., $3554 \mathrm{mg} / \mathrm{kg}$ ) but significantly higher than in Lycium chinense M. In fruit in fully ripe state diesterified carotenoids represented more than $98 \%$ of total, of which zeaxanthin dipalmitate was dominant $(2663 \pm 1536 \mathrm{mg} / \mathrm{kg})$ with $73 \pm 17 \%(p<0.05)$. This feature of the Goji berries is of great importance related to antioxidant activity as zeaxanthin dipalmitate has higher solubility and biodisponibility than free zeaxanthin. In fruits that did not reach full ripening maturity diesterified carotenoids represented less than $90 \%$ (90-73\%), while non-esterified carotenoids in the range 5-12\% lutein, $4-14 \%$ zeaxantain and $0.2-1 \% \beta$-carotene. The results led to the idea that Augus the optimum harvesting period for Goji berry in North Macedonia. 


\subsection{Statistical evaluation of nutritional and functional properties of Lycium barbarum L. variety cultivated in North Macedonia}

The variables under consideration for the statistical characterization of Macedonian Goji berry by PCA were mineral nutrients and proteins as \%RDA, TCC and sugar profile, antioxidant activity, TPC, polyphenol and carotenoid profiles. For Goji oil the parameters taken into account were FAs profile (SFAs, PUFAs, MUFAs) and lipid indices (PUFAs/SFAs ratio, n-6 and n-3 content, n-3/n-6 ratio, IA, IT, Cox and OS). Natrium and S were not considered, since no associated RDA values were set, while Mo was excluded because in all samples it was below the limit of detection in ICP-OES. Arsenic, $\mathrm{Pb}, \mathrm{Cd}, \mathrm{Hg}$ and $\mathrm{Ni}$ were ignored, since individual THQ and cumulative TTHQ indices revealed no health risk. Among antioxidant compounds, apigenine and quercitrine were also ignored in statistics because their content was below the detection limit in most samples.

The individual variables were assigned as strong (loading $>0.70$ ), moderate (loading $0.50-0.70$ ) or weak (loading 0.30-0.50) in each factor associated with a particular nutritional and functional property.

Factor loadings after Varimax rotation showed that four principal components described more than $90 \%$ of total variance in berry of Lycium barbarum L. variety cultivated in North Macedonia (Table 7).

The first factor (F1) accounting for $35.1 \%$ of total variance was associated to mineral nutrients, carbohydrates and proteins. Among minerals, $\mathrm{Mg}, \mathrm{K}, \mathrm{Cu}, \mathrm{Zn}, \mathrm{P}$ have a strong influence, while $\mathrm{Ca}, \mathrm{Mn}, \mathrm{Fe}$ a moderate one and reflect soil properties. Although $\mathrm{Cr}$ is included in this factor, its loading is slightly over 0.5 and can be neglected. This is consistent with the high variability of concentration as highlighted in Table 2. It can be noticed the inverse relationship of minerals with carbohydrates and MUFA, respectively. These correlations could be the result of the influence of soil minerals with direct impact on physiological and biochemical reaction in medicinal plant. Lycium barbarum L. variety is a halophytic plant with strong salt-resistance. Zheng et al. [37] showed that $\mathrm{Ca}^{2+}, \mathrm{Mg}^{2+}, \mathrm{Na}^{+}$, nitrogen and phosphorus available from soil have a strong influence on the decrease in accumulation of dominant carbohydrates (glucose, fructose) and thus TCC. The influence of minerals on the stability and content of unsaturated acids in medicinal plants and oils is mentioned in the literature. Zhang et al. [56] reported a significant decrease in the content of unsaturated C18 acids with low unsaturation degree in the oil of Paeonia ostii seeds as the content of $\mathrm{Cu}^{2+}$ increases in the soil, but especially as result of accumulation in the plant. This is explained by the prooxidative character of $\mathrm{Cu}^{2+}$ on unsaturated FAs with a significant positive correlation between peroxides of linoleic and linolenic acids and $\mathrm{Cu}$ in plant. A similar but smaller effect was observed from $\mathrm{Fe}^{2+}$ and $\mathrm{Mg}^{2+}$. In another study, Miyashita et al. [57] observed that oxidative stability of PUFAs in an aqueous solution with $\mathrm{Fe}^{2+}$-ascorbic acid increases with the number of carbon atoms and the degree of unsaturation. These remarks can be extrapolated to explain the negative correlation between MUFA and minerals in goji berries, however future research will be necessary to elucidate the relationship. F2 describing $22.3 \%$ of variability was associated to $\omega-6$ FAs and lipid indices of oil with cardioprotective effect (PUFAs, PUFAs/SFAs, $\mathrm{n}-6$, IA, IT, $\mathrm{c}_{\mathrm{ox}}$, OS). It can be remarked the small influence of the linolenic acid (C18:n-3) and of n-3/n-6 ratio on this factor. The significant positive influence of linoleic $(\mathrm{C} 18: 2 \mathrm{n}-6)$ acid and PUFAs on lipid indices is in agreement with FAs profile in oil from Macedonian goji berries. F3 (19.4\%) was mostly associated to nutrients with antioxidant activity like carotenoids and polyphenols belonging to anthocyanins class (delphinidin-3-orutoside) and less to phenolic acids (ellagic, ferulic, salycilic) and cinnamic acid. Salicylic acid has a moderate influence on the antioxidant activity and acts as modulator of polyphenolic acids and flavonoids synthesis [58]. Carotenoids describe 19-33\% of characteristics for berries of Lycium barbarum L. cultivated in North Macedonia. Copper has a low negative influence $(<0.5)$ on antioxidative capacity of carotenoids and polyphenols.

The factor (F4) describing $13.6 \%$ of total variance was attributed to $\omega-3$ FAs (n-3 PUFA and n-3/n- 6 ratio, loading factors $>0.70$ ) with beneficial influence on lipid indices of oil.

Grouping the tested variables using the 2D scatterplot of F1 (35.1\%) associated to mineral nutrients, carbohydrates and proteins and F2 (22.3\%) associated to $\omega-6$ FAs and lipid indices of oil are presented in Fig. 1 .

The scatterplot highlighted the four groups corresponding to nutritional and functional components of Lycium barbarum L. cultivated in North Macedonia. Similarities or lack of thereof between this variety and Lycium 
Table 7

Factor loadings after Varimax rotation of the first four PCs with eigenvalue $>1.0$ reflecting the contribution of each variable in grouping the nutritional and functional properties of Lycium barbarum L. berry cultivated in North Macedonia (loadings with strong influence $>0.700$ are marked in bold)

\begin{tabular}{|c|c|c|c|c|}
\hline Variable & $\begin{array}{c}\text { Factor } 1 \text { Mineral } \\
\text { nutrients, carbohydrates } \\
\text { and proteins }\end{array}$ & $\begin{array}{c}\text { Factor } 2 \omega-6 \\
\text { Fatty acids and lipid } \\
\text { indices of oil }\end{array}$ & $\begin{array}{c}\text { Factor } 3 \text { Nutrients } \\
\text { with antioxidant } \\
\text { activity }\end{array}$ & $\begin{array}{c}\text { Factor } 4 \omega-3 \\
\text { Fatty acids }\end{array}$ \\
\hline Proteins & 0.761 & 0.216 & 0.003 & 0.468 \\
\hline $\mathrm{Mg}$ & 0.760 & 0.320 & 0.262 & 0.404 \\
\hline $\mathrm{K}$ & 0.744 & -0.081 & -0.396 & 0.358 \\
\hline $\mathrm{Ca}$ & 0.577 & -0.581 & -0.196 & 0.411 \\
\hline $\mathrm{Mn}$ & 0.696 & 0.217 & 0.132 & 0.068 \\
\hline $\mathrm{Fe}$ & 0.647 & 0.325 & 0.016 & -0.083 \\
\hline $\mathrm{Cu}$ & 0.780 & 0.082 & 0.449 & 0.414 \\
\hline $\mathrm{Zn}$ & 0.929 & -0.037 & 0.083 & 0.162 \\
\hline $\mathrm{P}$ & 0.735 & 0.412 & 0.208 & 0.374 \\
\hline $\mathrm{Cr}$ & -0.515 & 0.115 & -0.157 & -0.425 \\
\hline SFAs & 0.036 & -0.963 & 0.100 & -0.150 \\
\hline MUFAs & -0.849 & -0.334 & -0.345 & -0.005 \\
\hline PUFAs & 0.369 & 0.897 & 0.084 & 0.117 \\
\hline PUFAs/SFAs & 0.015 & 0.983 & -0.012 & 0.120 \\
\hline$n-6$ & 0.370 & 0.800 & 0.051 & 0.382 \\
\hline$n-3$ & -0.123 & 0.003 & 0.072 & -0.840 \\
\hline$n-3 / n-6$ & -0.190 & -0.078 & 0.044 & -0.836 \\
\hline IA & 0.482 & -0.841 & -0.070 & -0.047 \\
\hline IT & 0.380 & -0.816 & -0.047 & 0.375 \\
\hline Cox & 0.286 & 0.892 & 0.100 & -0.228 \\
\hline OS & 0.298 & 0.875 & 0.110 & -0.257 \\
\hline PCL & -0.483 & -0.214 & -0.807 & -0.003 \\
\hline DPPH & -0.375 & -0.401 & -0.780 & -0.140 \\
\hline ABTS & -0.292 & -0.387 & -0.796 & -0.333 \\
\hline ТPC & -0.019 & 0.022 & -0.838 & -0.328 \\
\hline GLU & -0.920 & 0.182 & 0.115 & 0.080 \\
\hline FRU & -0.892 & 0.002 & 0.033 & -0.222 \\
\hline TCC & -0.935 & 0.092 & 0.179 & 0.023 \\
\hline $\mathrm{CA}$ & -0.440 & -0.676 & -0.210 & -0.175 \\
\hline EA & 0.256 & -0.298 & -0.480 & -0.019 \\
\hline FA & -0.566 & -0.035 & -0.268 & 0.295 \\
\hline SA & 0.421 & -0.328 & 0.636 & 0.181 \\
\hline DR & -0.301 & -0.134 & -0.742 & 0.524 \\
\hline LU & 0.140 & 0.055 & -0.931 & 0.240 \\
\hline ZE & 0.151 & 0.029 & -0.926 & 0.238 \\
\hline bCR & 0.099 & 0.049 & -0.814 & 0.517 \\
\hline ATD & 0.309 & -0.229 & -0.429 & 0.578 \\
\hline ZMP & -0.077 & 0.571 & 0.090 & 0.728 \\
\hline ZD & 0.182 & -0.139 & 0.545 & 0.530 \\
\hline Total Variance (\%) & 35.1 & 22.3 & 19.4 & 13.6 \\
\hline Cumulative variance (\%) & 35.1 & 57.4 & 76.8 & 90.4 \\
\hline
\end{tabular}




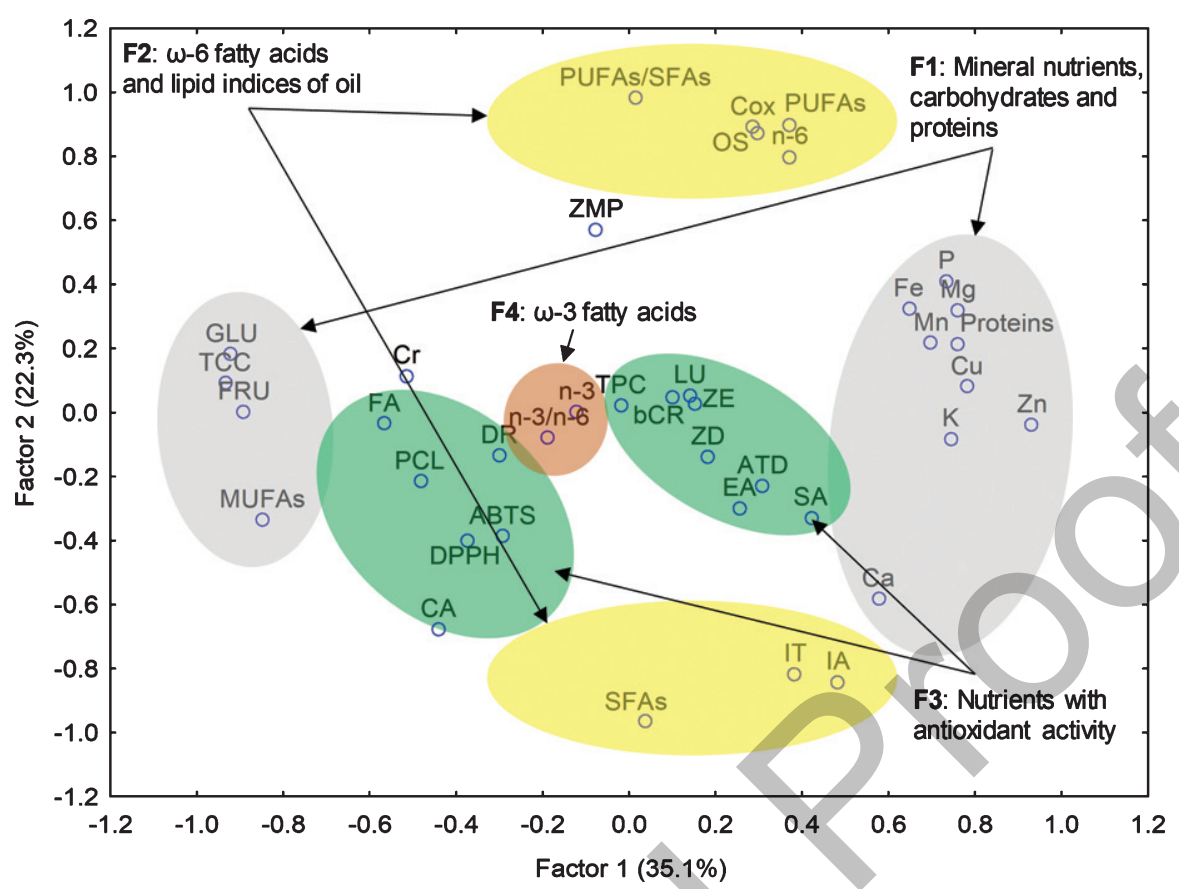

Fig. 1. The 2D scatterplot of the first two varimax-rotated PCA factors showing the relationships between the main variables for Lycium barbarum L. cultivated in North Macedonia. SFAs-saturated fatty acids; IA-artherogenic index; IT-thrombogenic index; TPC-total phenolic content; PCL-photochemiluminescence assay; DPPH assay; ABTS assay; MUFAs-monounsaturated fatty acids; PUFAs-polyunsaturated fatty acids; n-6- $\omega$-6PUFA; n-3 - $\omega$-3PUFA; Cox-oxidisability value; OS-oxidative susceptibility; GLU-glucose; FRU-fructose; TCC-total carbohydrates; CA-cinnamic acid; EA-ellagic acid; FA-ferulic acid; SA-salicylic acid; DR- delphinidin-3-o-rutoside; LU-(all-E)-lutein, ZE-(all-E)-zeaxanthin, bCR-(all-E)- $\beta$-carotene; ATD-(all-E)-antheraxanthin dipalmitate, ZMP-(all-E)-zeaxanthin miristate palmitate; ZD-(all-E)-zeaxanthin dipalmitate.

chinense M. could be easily observed in the heat map after two-way joining analysis as a clustering method (Fig. 2).

The picture emphasizes significantly different patterns for the two Goji varieties mostly in terms of inorganic nutrients, antioxidant capacity, proteins, sugar profile and some lipid indices such as n-3 FAs and n-3/n-6 ratio. The observation is consistent with outcomes in Varimax rotation, which shows that mineral nutrients, carbohydrates and proteins have the greatest influence on the variability of properties of Lycium barbarum L. Also, taking into account only fruits harvested at full maturity (samples 4,5,7,9), Lycium Barbarum L. differs significantly in terms of diesterified carotenoids, zeaxanthin dipalmitate and zeaxanthin miristate palmitate.

\section{Conclusions}

Characterization in terms of elemental composition, sugar profile, FAs in oil, carotenoids, polyphenols and proteins highlighted that nutritional and functional properties of berries from Lycium barbarum L. variety cultivated in North Macedonia are significantly different from Lycium chinense M. It was established that Goji cultivated in North Macedonia is a rich source of mineral nutrients ( $\mathrm{K}, \mathrm{Cu}, \mathrm{Mn}, \mathrm{P}, \mathrm{Fe}, \mathrm{Mg}$ and $\mathrm{Zn}$ ), compounds with antioxidative property such as esterified carotenoids, mainly zeaxanthin dipalmitate, and anthocyanins (delphinidin-3-o-rutoside). The lipid profile of FAs dominated by PUFAs, high PUFAs/SFAs ratio, low atherogenic, thrombogenic indices and oxidisability capacity, and high oxidation susceptibility may exert a positive 


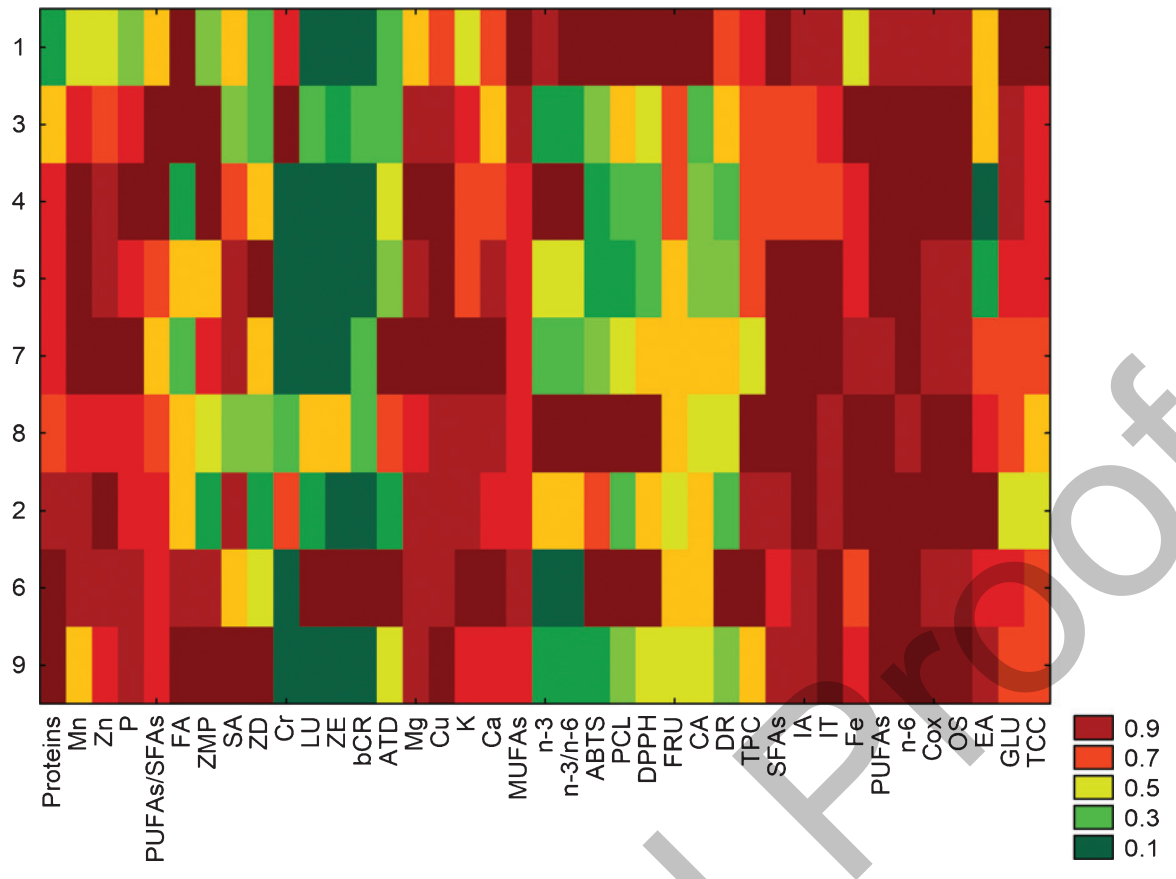

Fig. 2. Heat map after two-way joining analysis as clustering method to emphasize similarities or lack of thereof between Lycium barbarum L. and Lycium chinense M. varieties. SFAs-saturated fatty acids; IA-artherogenic index; IT-thrombogenic index; TPC-total phenolic content; PCL-photochemiluminescence assay; DPPH assay; ABTS assay; MUFAs-monounsaturated fatty acids; PUFAs-polyunsaturated fatty acids; n-6- $\omega$-6PUFA; n-3- $\omega$-3PUFA; Cox-oxidisability value; OS-oxidative susceptibility; GLU-glucose; FRU-fructose; TCC-total carbohydrates; CA-cinnamic acid; EA-ellagic acid; FA-ferulic acid; SA-salicylic acid; DR- delphinidin-3-o-rutoside; LU-(all-E)-lutein, ZE-(all-E)-zeaxanthin, bCR-(all-E)- $\beta$-carotene; ATD-(all-E)-antheraxanthin dipalmitate, ZMP-(all-E)-zeaxanthin miristate palmitate; ZD-(all-E)-zeaxanthin dipalmitate.

influence on many metabolic functions in the human body. However, n-3/n-6 ratio was below that considered optimal for health because the low concentration of linolenic acid could not balance n-6 PUFA, as remarked in other vegetable oils. Toxic elements found in very low concentrations pose no risk to consumers. Combination of chemical characterization with chemometrics was useful for deepening the knowledge about goji berry and identifying factors associated with nutritional and functional properties. Thus PCA allowed grouping nutritional components and those with bioactive properties as: (1) mineral nutrients, carbohydrates and proteins (35.1\%); (2) $\omega$-6 FAs and lipid indices of oil (22.3\%); (3) antioxidant activity of carotenoids and polyphenols (19.4\%) and (4) $\omega$-3 FAs $(13.6 \%)$. Carotenoid profile and sugars revealed differences in terms of ripening stage of the analyzed berries. Thus, diesterified carotenoids found mostly in fully ripened fruits were not included in a single factor, however described up to $33 \%$ of variability for bioactive properties. The heat map revealed significantly different patterns for berries of Lycium barbarum L. and Lycium chinense M. varieties in terms of inorganic nutrients, antioxidative capacity, protein, n-3 PUFA and n-3/n-6 ratio, as well as zeaxanthin dipalmitate and zeaxanthin miristate palmitate. Overall berry of Lycium barbarum L. cultivated in North Macedonia has proved to be an effective natural dietary supplement.

\section{Acknowledgments}

This work was supported by a grant of Ministry of Research and Innovation. 
Romania, project number 33PFE/2018, within PNCDI III.

This work was also supported by a grant of Ministry of Research and Innovation, Romania, project PROINSTITUTIO - Contract no.19PFE/17.10.2018.

\section{Conflict of interest}

The authors have no conflict of interest to report.

\section{Funding}

The authors report no funding.

\section{References}

[1] Auzanneau N, Weber P, Kosinska-Cagnazzo A, Andlauer W. Bioactive compounds and antioxidant capacity of Lonicera caerulea berries: Comparison of seven cultivars over three harvesting years. J Food Compos Anal. 2018;66:81-9.

[2] Chang SK, Alasalvar C, Shahidi F. Review of dried fruits: Phytochemicals, antioxidant efficacies, and health benefits. J Funct Foods. 2016;21:113-32.

[3] Guo MC, Shi TY, Duan YH, Zhu JL, Li JQ, Cao YS. Investigation of amino acids in wolfberry fruit (Lycium barbarum) by solid-phase extraction and liquid chromatography with precolumn derivatization. J Food Compos Anal. 2015;42:84-90.

[4] Llorent-Martinez EJ, Fernandez de Cordova ML, Ortega-Barrales P, Ruiz-Medina A. Characterization and comparison of the chemical composition of exotic superfoods. Microchem J. 2013;110:444-51.

[5] Moreda-Pineiro J, Sanchez-Pineiro J, Manana-Lopez A, Turnes-Carou I, Alonso-Rodriguez E, Lopez-Mahia P, Muniategui-Lorenzo S. Multi-element determinations in food from Amazon region by ICP-MS after enzymatic hydrolysis assisted by pressurisation and microwave energy. Microchem J. 2018;137:402-9.

[6] Juranovic Cindric I, Zeiner M, Krpetic M, Stingeder G. ICP-AES determination of minor and major elements in Cornelian cherry (Cornus mas L.) after microwave assisted digestion. Microchem J. 2012;105:72-6.

[7] Blasi F, Montesano D, Simonetti MS, Cossignani L. A simple and rapid extraction method to evaluate the fatty acid composition and nutritional value of goji berry lipid. Food Anal Meth. 2017;10:970-79.

[8] Cossignani L, Blasi F, Simonetti MS, Montesano D. Fatty acids and phytosterols to discriminate geographic origin of Lycium barbarum berry. Food Anal Meth. 2018;11:180-1188.

[9] Jeszka-Skowron M, Zgola-Grzeskowiak A, Stanisz E, Waskiewicz A. Potential health benefits and quality of dried fruits: Goji fruits, cranberries and raisins. Food Chem. 2017;221:228-36.

[10] Kafkaletou M, Christopoulos MV, Tsaniklidis G, Papadakis I, Ioannou D, Tzoutzoukou C, Tsantili E. Nutritional value and consumerperceived quality of fresh goji berries (Lycium barbarum L. and L. chinense L.) from plants cultivated in Southern Europe. Fruits. 2018;73:5-12.

[11] Kosinska-Cagnazzo A, Weber B, Chablais R, Vouillamoz JF, Molnar B, Crovadore J, Lefort F, Andlauer W. Bioactive compound profile and antioxidant activity of fruits from six goji cultivars cultivated in Switzerland. J Berry Res. 2017;7:43-59.

[12] Mocan A, Moldovan C, Zengin G, Bender O, Locatelli M, Simirgiotis M, Atalay A, Vodnar DC, Rohn S, Crisan G. UHPLC-QTOFMS analysis of bioactive constituents from two Romanian Goji (Lycium barbarum L.) berries cultivars and their antioxidant, enzyme inhibitory, and real-time cytotoxicological evaluation. Food Chem Toxicol. 2018;115:414-24.

[13] Niro S, Fratianni A, Panfili G, Falasca L, Cinquanta L, Alam MR. Nutritional evaluation of fresh and dried Goji Berries cultivated in Italy. Ital J Food Sci. 2017;29:398-408.

[14] Montesano D, Cossignani L, Giua L, Urbani E, Simonetti MS, Blasi F. A simple HPLC-ELSD Method for Sugar Analysis in Gojy Berry. J Chem. 2016; Art ID 6271808

[15] Skenderidis P, Lampakis D, Giavasis I, Leontopoulos S, Petrotos K, Hadjichristodoulou C, Tsakalof A. Chemical Properties, FattyAcid Composition, and Antioxidant Activity of Goji Berry (Lycium Barbarum L. and Lycium chinense Mill.) Fruits. Antioxidants 2019;8:1-13. 
[16] Bertoldi D, Cossignani L, Blasi F, Perini M, Barbero A., Pianezze S, Montesano, D. Characterisation and geographical traceability of Italian goji berries. Food Chem. 2019; 275:585-93.

[17] Hempel J, Schadle CN, Sprenger J, Heller A, Carle R, Schweiggert RM. Ultrastructural deposition forms and bioaccessibility of carotenoids and carotenoid esters from goji berries (Lycium Barbarum L.). Food Chem. 2017;218:525-33.

[18] Kulczyński B, Gramza-Michalowska A. Goji Berry (Lycium barbarum): Composition and Health Effects-a Review. Pol J Food Nutr Sci. 2016;66:67-75.

[19] Masci A, Carradori S, Casadei MA, Paolicelli P, Petralito S, Ragno R, Cesa S. Lycium barbarum polysaccharides: Extraction, purification, structural characterisation and evidence about hypoglycaemic and hypolipidaemic effects. A review. Food Chem. 2018;254:377-89.

[20] Wawruszak A, Czerwonka A, Okla K, Rzeski W. Anticancer effect of ethanol Lycium barbarum (Goji berry) extract on human breast cancer T47D cell line. Nat Prod Res. 2016;30:1993-6.

[21] Jacquenet S, Richard C, Hofmann B. Goji berry food allergy: Current state and knowledge. Rev Fr Allergol. 2017;57:426-29.

[22] Kosinska-Cagnazzo A, Bocquel D, Marmillod I, Andlauer W. Stability of goji bioactives during extrusion cooking process. Food Chem. 2017;230:250-56.

[23] Asanica A, Manole C, Tudor V, Dobre A, Teodorescu RI. Lycium barbarum L. juice-natural source of biologically active compounds. AgroLife Sci J. 2016;5:15-20.

[24] Blasi F, Rocchetti G, Montesano D, Lucini L, Chiodelli G, Ghisoni S, Baccolo G, Simonetti MS, Cossignani, L. Changes in extra-virgin olive oil added with Lycium barbarum L. carotenoids during frying: Chemical analyses and metabolomic approach. Food Res Int. 2018;105:507-16.

[25] Ducruet J, Rebenaque P, Diserens S, Kosinska-Cagnazzo A, Heritier I, Andlauer W. Amber ale beer enriched with goji berries-The effect on bioactive compound content and sensorial properties. Food Chem. 2017;226:109-18.

[26] Ferreira JMM, Azevedo BM, Luccas V, Bolini HMA. Sensory profile and consumer acceptability of prebiotic white chocolate with sucrose substitutes and the addition of goji berry (Lycium barbarum). J Food Sci. 2017;82:818-24.

[27] Pedro AC, Maurer JBB, Zawadzki-Baggio SF, Avila S, Maciel GM, Haminiuk CWI. Bioactive compounds of organic goji berry (Lycium barbarum L.) prevents oxidative deterioration of soybean oil. Ind Crop Prod. 2018;112:90-97.

[28] Dzhugalov H, Lichev V, Yordanov A, Kaymakanov P, Dimitrova V, Kutoranov G. First results of testing goji berry (Lycium barbarum L.) in Plovdiv region, Bulgaria. Scientific Papers. Series B. Horticulture. 2015;59:47-50.

[29] Dubois M, Gilles KA, Hamilton JK, Rebers PA, Smith F. Colorimetric method for determination of sugars and related substances. Anal Chem. 1956;28:350-356.

[30] Skenderidis P, Kerasioti E, Karkanta E, Stagos D, Kouretas D, Petrotos K, Hadjichristodoulou C, Tsakalof A. Assessment of the antioxidant and antimutagenic activity of extracts from goji berry of Greek cultivation. Toxicol Rep. 2018;5:251-57.

[31] Farag S. Separation and analysis of some sugars by using thin layer chromatography. J Sugar Beet Res. 1979;20:251-54.

[32] Mariotti F, Tome D, Mirand PP. Converting nitrogen into protein-beyond 6.25 and Jones' factors. Crit Rev Food Sci Nutr.2008;48:177-84.

[33] FAO/WHO (Food and Agricultural Organization of the United Nations and World Health Organization). Fats and fatty acids in human nutrition. Report of an extract consultation. FAO Food Nutr Pap. 2010:91 Rome.

[34] Ulbricht TLV, Southgate DAT. Coronary heart disease: seven dietary factors. The Lancet. 1991;338:985-992.

[35] Mot AC, Damian G, Sarbu C, Silaghi-Dumitrescu R. Redox reactivity in propolis: Direct detection of free radicals in basic medium and interaction with hemoglobin. Redox Rep. 2009;14:267-74.

[36] Pintea A, Diehl HA, Momeu C, Aberle L, Socaciu C. Incorporation of carotenoid esters into liposomes. Biophys Chem. 2005; 118:7-14

[37] Zheng GQ, Zheng ZY, Xu X, Hu ZH. Variation in fruit sugar composition of Lycium barbarum L. and Lycium chinense Mill. of different regions and varieties. Biochem Syst Ecol. 2010;38:275-84.

[38] Wolfe RR, Cifelli AM, Kostas G, Kim IY. Optimizing Protein Intake in Adults: Interpretation and Application of the Recommended Dietary Allowance Compared with the Acceptable Macronutrient Distribution Range. Adv Nutr. 2017;8:266-75

[39] Yu X, Gao Y, Zhao Z, Gao JM. Rapid Determination of Amino Acids in Chinese Wolfberry (Lycium barbarum L.) Fruit by Using Fourier Transform Infrared Spectroscopy and Partial Least Square Regression. Food Anal Methods. 2017;10:2436-43.

[40] Nascimento AN, Silvestre DM, Leme FO, Nomura CS, Naozuka J. Elemental analysis of goji berries using axially and radially viewed inductively coupled plasma-optical emission spectrometry. Spectroscopy. 2015;30:36-41.

[41] Commission Regulation (EC) No. 1169/2011 on the provision of food information to consumers. Off J Eur Union. L 304/18.

[42] Wojcieszek J, Kwiatkowski P, Ruzik L. Speciation analysis and bioaccessibility evaluation of trace elements in goji berries (Lycium Barbarum, L.). Journal of Chromatography A. 2017;1492:70-8.

[43] Commission Regulation (EC) No. 1881/2006 setting maximum levels for certain contaminants in foodstuffs. Off J Eur Union. L364/5. 
[44] European Food Safety Authority (EFSA). Cadmium in food. Scientific opinion of the panel on contaminants in the food chain. EFSA J. 2010;980:1-139. Lead in food. Scientific opinion of the panel on contaminants in the food chain. EFSA J. 2009;8:1-151. Scientific report on Dietary exposure to inorganic arsenic in the European population. EFSA J. 2014;12:3597 (1-68??). Scientific opinion on the risk for public health related to the presence of mercury and methylmercury in food. EFSA J. 2012;10:2985 (1-141 ??).

[45] US EPA (2013): Reference dose (RfD): Description and use in health risk assessments, Background Document 1A, Integrated risk information system (IRIS); United States Environmental Protection Agency: Washington, DC, 15 March 2013; http://www.epa.gov/iris/rfd.htm.

[46] Rosa A, Maxia A, Putzu D, Atzeri A, Era B, Fais A, Sanna C, Piras A. Chemical composition of Lycium europaeum fruit oil obtained by supercritical $\mathrm{CO}_{2}$ extraction and evaluation of its antioxidant activity, cytotoxicity and cell absorption. Food Chem. 2017;230:82-90.

[47] Simopoulos AP, Cleland LG. Omega-6/omega-3 essential fatty acid ratio. The scientific evidence. Karger, World Rev Nutr Diet. Basel. 2003;92.

[48] Candela CG, López LMB, Kohen VL. Importance of a balanced omega 6/omega 3 ratio for the maintenance of health. Nutritional recommendations. Nutr Hosp. 2011;26:323-9.

[49] Montesano D, Rocchetti G, Cossignani L, Lucini L, Simonetti MS, Blasi F. Italian Lycium barbarum L. Berry: Chemical Characterization and Nutraceutical Value. NPC Nat Prod Commun. 2018;13:1151-6.

[50] Martin CA, Visentainer JV, de Oliveira AN, de Oliveira CC, Matsushita M, de Souza NE. Fatty acid contents of Brazilian Soybean oils with emphasis on trans fatty acids. J Braz Chem Soc. 2008;19:117-22.

[51] Boudour-Benrachou N, Plard J, Pinatel C, Artaud J, Dupuy N. Fatty acid compositions of olive oils from six cultivars from East and South-Western Algeria. Adv Food Technol Nutr Sci Open J. 2017;3:1-5.

[52] Petrovic M, Kezic N, Bolanca V. Optimization of the GC method for routine analysis of the fatty acid profile in several food samples. Food Chem. 2010;122:285-91.

[53] Brauch JE, Buchweitz M, Schweiggert, Carle R. Detailed analyses of fresh and dried maqui (Aristotelia chilensis (Mol.) Stuntz) berries and juice. Food Chem. 2016;190:308-16.

[54] Zhao BB, Gong HD, Li H, Zhang Y, Lan T, Chen ZC. Characterization of Chinese grape seed oil by physicochemical properties, fatty acid composition, triacylglycrol profiles, and sterols and squalene composition. Int J Food Eng. 2019;15 DOI: https://doi.org/10.1515/ijfe-2019-0031

[55] Ennigrou A, Casabianca H, Laarif A, Hanchi B, Hosni K. Maturation-related changes in phytochemicals and biological activities of the Brazilian pepper tree (Schinus terebinthifolius Raddi) fruits. S Afr J Bot. 2017;108:407-15.

[56] Zhang ZH, Wang H, Liu J, Qin W, Zhu MY, Zu YG, Tang ZH. The effects of soil metals on the composition of oil of Paeonia ostii seeds. J Plant Interac. 2015;10:288-95.

[57] Miyashita K, Nara E, Ota T. Oxidative stability of polyunsaturated fatty acids in an aqueous solution. Biosci Biotech Biochem. 1993;57:1638-40.

[58] Dias-Rivas JO, Gonzales-Laredo JO, Chaves-Simental JA, Montoya-Ayon JB, Moreno-Jimenes MR, Gallegos-Infante JA, RochaGUzman NE. Comprehensive characterization of extractable phenolic compounds by UPLC-PDA-ESI-QqQ of Buddleja scordioides plants elicited with salicylic acid. J Chem. 2018; Article ID 4536970, 10 pages, https://doi.org/10.1155/2018/4536970. 